\title{
Percutaneous radiofrequency lesioning of the suprascapular nerve for the management of chronic shoulder pain: a case series
}

This article was published in the following Dove Press journal:

Journal of Pain Research

20 April 2012

Number of times this article has been viewed

\section{Thomas T Simopoulos \\ Jyotsna Nagda \\ Musa MAner}

Arnold Pain Management Center Beth Israel Deaconess Medical Center, Harvard Medical School, Boston, MA, USA
Correspondence: Thomas T Simopoulos Arnold Pain Management Center, Beth Israel Deaconess Medical Center, Harvard Medical School, 330 Brookline Avenue, Boston, MA 02215, USA

$\mathrm{Tel}+\mid \mathrm{l} 617278803$ |

Fax +I 6172788065

Email tsimopou@bidmc.harvard.edu
Purpose: The objective of this study was to retrospectively evaluate the analgesic effects of continuous radiofrequency lesioning of the suprascapular nerve (SSN) for chronic shoulder pain. The authors sought to obtain insight into the time-sensitive analgesic success and complications of this therapy.

Patients and methods: This study was a retrospective case series involving patients with unremitting shoulder pain that had lasted for at least 12 months. Patients were selected if they showed a reduction of at least $50 \%$ in pain intensity during the anesthetic phase after SSN block, no additional motor weakness of the shoulder, and pain relief lasting for less than 2 months after separate treatments of the SSN with depot corticosteroids and pulsed radiofrequency. Nine patients were referred to the Arnold Pain Management Center. Of these nine patients, six patients who had significant chronic shoulder pain unresponsive to oral medications and intra-articular injections and who were not considered surgical candidates were selected. These patients were treated with a single radiofrequency lesion of the $\mathrm{SSN}$ at $80^{\circ} \mathrm{C}$ for 60 seconds. The primary outcome was a reduction in pain intensity by $50 \%$, as determined by the numeric rating scale, and duration of this effect. The secondary outcome was improvement in either the passive or the active range of motion (ROM). Patients were also monitored for adverse effects such as weakness or increased pain.

Results: The pooled mean numeric rating scale score before the procedure was $7.2 \pm 1.2$; this fell to $3.0 \pm 0.9$ at 5-7 weeks post procedure. The duration of pain relief ranged from 3 to 18 months, and all patients underwent at least one additional treatment. The change in baseline ROM improved from an average of $60^{\circ} \pm 28^{\circ}$ (flexion) and $58^{\circ} \pm 28^{\circ}$ (abduction) to $99^{\circ} \pm 46^{\circ}$ (flexion) and $107^{\circ} \pm 39^{\circ}$ (abduction). No adverse side effects were observed.

Conclusion: Continuous radiofrequency lesioning of the SSN seems to be an effective treatment for chronic shoulder pain. There can be improved ROM of the shoulder following this treatment. More formal, controlled studies are required to confirm these observations.

Keywords: pulsed radiofrequency, suprascapular nerve block, pain relief, range of motion

\section{Introduction}

Chronic shoulder pain is a frequent clinical condition that often reduces a patient's function and rehabilitation potential. The most common etiologies of chronic shoulder disorders include rotator cuff syndrome, glenohumeral joint osteoarthritis, adhesive capsulitis, posttraumatic pain, and persistent pain following surgery. ${ }^{1}$ Not uncommonly, conventional pharmacotherapy may either have too many side effects or be ineffective. Physical therapy is often abandoned because of persistent intolerable pain, and a progressive decline in range of motion (ROM) and function ensues. Furthermore, a substantial number of patients may not be appropriate surgical candidates or they may have significant medical comorbidities. 
Suprascapular nerve block (SSNB) has a long history of reducing pain and improving ROM in patients with shoulder pain. ${ }^{2}$ The suprascapular nerve (SSN) innervates nearly $70 \%$ of the shoulder joint, and therefore its blockade is a commonly accepted mode of pain therapy in acute and chronic settings. ${ }^{3}$ Pain relief from a SSNB may last for hours only but relief can be more prolonged if depot steroids are added. ${ }^{4}$ Nonetheless, the number of patients with time-sensitive analgesia too brief to be clinically practical is significant.

More recently, pulsed radiofrequency (PRF) treatment of the SSN has emerged as an alternative mode for prolonged relief of chronic shoulder pain..$^{5-7}$ PRF is a very attractive mode of treatment because of its minimally destructive nature. ${ }^{8}$ Despite its exact mechanism of action being unclear, PRF has particular advantages when treating mixed sensory and motor peripheral nerves. In comparison with neurolytic techniques, PRF treatment is felt to function at a more neuromodulatory level, and therefore the risks of deafferentation, neuritis, and neuroma formation are felt to be minimal. ${ }^{5}$ Repeat treatments via PRF are easily achieved because the target nerve is left intact. Finally, application of PRF to the SSN does not risk paralysis of the supraspinatus and infraspinatus muscles.

However, the authors have encountered a series of patients with intractable shoulder pain who responded to both SSNB and PRF of the SSN for a short-lived duration. The authors describe the selection of patients based on preexisting motor function and SSNB with local anesthetic. The patients underwent continuous (or conventional) radiofrequency (CRF) lesioning of the SSN in order to derive more sustained benefit.

\section{Methods}

Over two years, nine patients were referred to the Arnold Pain Management Center (Brookline, MA) with severe chronic shoulder pain. In addition to a careful history and physical examination, a diagnosis of anatomic pathology was made in each patient with magnetic resonance imaging. The patients were treated conservatively with extensive physical therapy, intra-articular steroid injections, trigger point injections, nonsteroidal anti-inflammatory drugs, and opioids. None of the patients were considered suitable candidates for surgery.

In addition, all patients underwent a diagnostic SSNB after initial evaluation. The SSNB was performed with the use of fluoroscopy, with the patient in either the prone or the sitting position. A 22-gauge spinal needle was advanced to the suprascapular notch and $5 \mathrm{~mL}$ of $2 \%$ lidocaine with depot methylprednisolone acetate $(20 \mathrm{mg})$. In order to be considered for PRF treatment $\left(42^{\circ} \mathrm{C}\right.$ for 120 seconds at each time) the following criteria had to be met: (1) a decline of at least $50 \%$ in the numeric rating scale (NRS) score on anesthetic phase and (2) pain relief lasting for less than 2 months. Six of the nine patients met these criteria.

To be considered for CRF, all conditions for PRF had to be fulfilled as well as the failure of PRF to provide at least 2 months of pain relief. In addition, for patients who had any active mobility of the shoulder, motor testing was performed after a repeat SSNB with $2 \mathrm{~cm}^{3}$ of $5 \%$ lidocaine. Motor testing via standard physical examination, graded from 0 (no evidence of contractility) to 5 (complete range of motion against gravity, with full resistance), focused on those muscles innervated by the SSN that included abduction (supraspinatus) and external rotation (infraspinatus). CRF treatment was not offered if the patient or the examining physician noticed any shoulder weakness.

The fluoroscopic approach used in nerve blockade, PRF treatment, and CRF treatment has been well described in the past and was employed in this case series. ${ }^{5}$ In summary, the patients were placed on the fluoroscopy table in the prone position with his or her arm tucked to the side. The sitting position was used for the hemiplegic patients who could not tolerate the prone position (Figure 1). In either position, under $\mathrm{C}$-arm fluoroscopy, the electrode was guided to the apex of the suprascapular notch. The suprascapular notch was identified in an immediate proximal and medial position to the coracoid process; this is because of the "rounded shoulder" posture of patients with chronic shoulder pain. To delineate between the two structures it is necessary for the $\mathrm{C}$-arm to be at an oblique angle of $15^{\circ}-25^{\circ}$, since the coracoid blocks the view of the suprascapular notch, particularly in the sitting position (Figure 2). Also, a cephalocaudal angle $\left(15^{\circ}-25^{\circ}\right)$ must be added to visualize the spine of the scapula, the prone position was again more advantageous for this (Figure 3).

The proximity of a 22-gauge SMK C5 electrode $(51 \mathrm{~mm}$, $4 \mathrm{~mm}$ active tip; Radionics, Burlington, MA) to the SSN was determined by sensory stimulation at $50 \mathrm{~Hz}$. Reproducible paresthesias covering the shoulder joint (mostly the posterior aspect) were elicited at a voltage range of $0.1-0.5 \mathrm{~V}$. Motor stimulation at $2 \mathrm{~Hz}$ produced objective contractions of the supraspinatus and infraspinatus muscle groups at a range of $0.1-0.85 \mathrm{~V}$. A single radiofrequency thermocoagulation lesion was performed at $80^{\circ} \mathrm{C}$ for 60 seconds using a radiofrequency generator (RFG-3B; Radionics, Burlington, MA).

The primary clinical outcome measure was a reduction in pain intensity as determined by the NRS (an eleven-point scale, from 0 to 10 ). A $50 \%$ or greater reduction in the NRS 


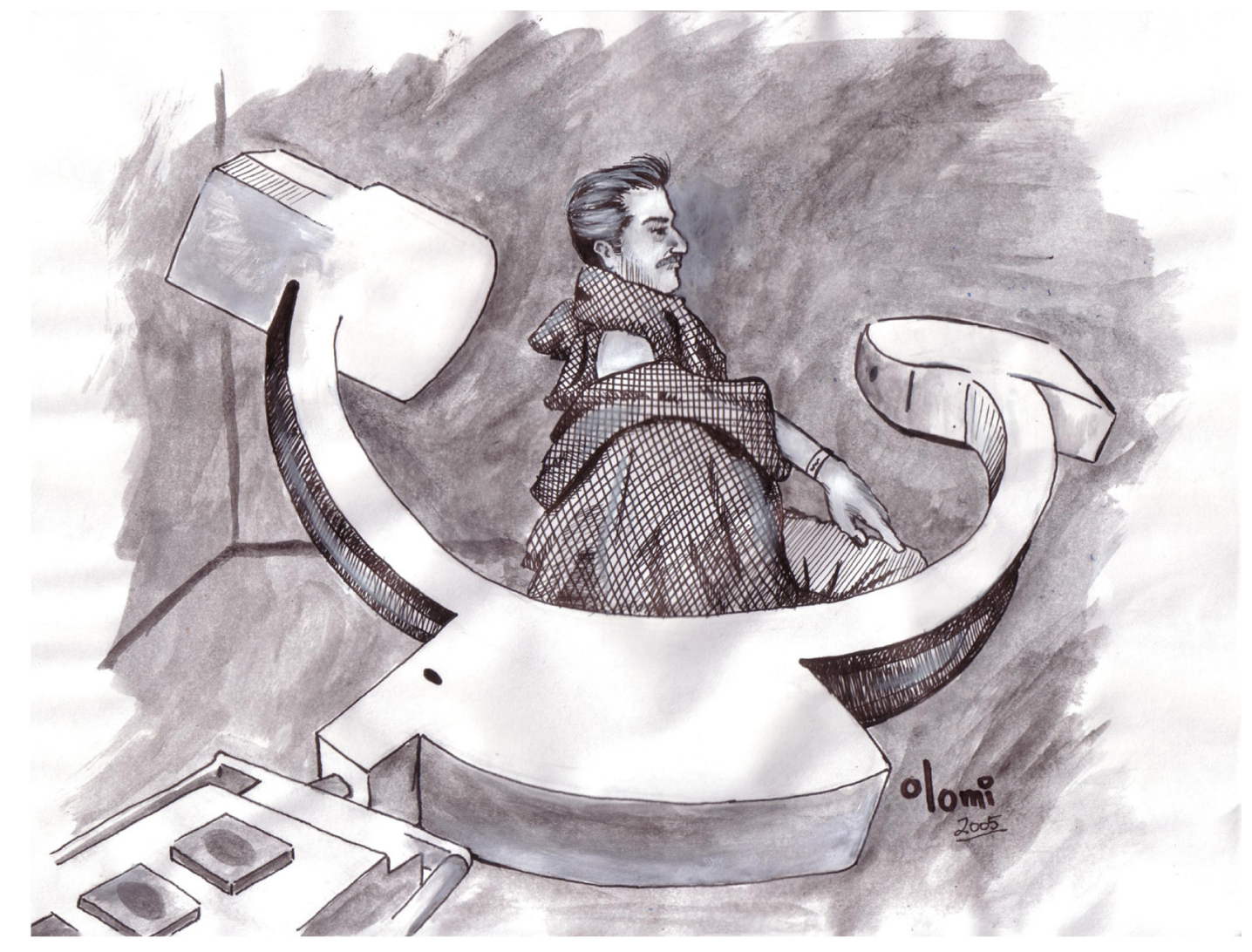

Figure I When visualizing the suprascapular notch under fluoroscopy, certain patients may find the only tolerable position to be the sitting position. Copyright (C) 2009, ASIPP Publishing. Adapted with permission from Sial KA, Simopoulos TT, Malik AB. Suprascpular nerve block. In: Interventional Techniques in Chronic Non-spinal Pain. Peducah, KT: ASIPP Publishing; 2009.

Note: The Positioning of the $\mathrm{C}$-arm at an oblique angle of $15^{\circ}-25^{\circ}$ and a cephalocaudal angle of approximately $15^{\circ}-25^{\circ}$.

score following the procedure was defined as "effective." Serial treatment were offered when this criterion was met. Secondary clinical outcome measures were improvements in the ROM of the glenohumeral joint, which included passive ROM for those patients with significant loss of shoulder mobility and active ROM for those patients with preserved motor function. Flexion and abduction were most limited in this selected group of patients and were consistently evaluated and recorded. Motor testing was performed using a graded scale from 0 to 5 where 5 represents full motor strength and 0 is no movement. The time-sensitive success of CRF lesioning was monitored by routine clinical follow-up at 5-7 weeks post procedure. Lastly, adverse events such as loss of function and perceived or objective weakness of the rotator cuff muscles, as determined by the physical examination, were carefully assessed. Worsening pain that could signify potential neuritis was screened for in follow-up visits. All data including NRS scores, ROM, number of repeat CRF procedures, and details of any adverse events were collected retrospectively from the electronic and paper charts. The change in the visual analogue scale score associated with pain pre-CRF to post-CRF treatment was then subjected to statistical evaluation using a two-tailed Student's $t$-test.

\section{Results}

The mean age of the patients in this study was 54 years (Table 1 ). These patients had been suffering from chronic shoulder pain for an average of 2.3 years before the study. The duration of pain relief from SSNB and PRF treatment ranged from 1 to 5 days and 1 to 4 weeks, respectively. In this retrospective case series, the pooled mean NRS score was $7.2 \pm 1.2$, declining to $3.0 \pm 0.9$ $(P<0.01)$ at $5-7$ weeks post procedure. Table 2 summarizes the time-sensitive pain relief and the number of repeat procedures with similar impact on pain intensity and duration.

The effects of pain reduction on shoulder ROM increased modestly from a baseline average of $60^{\circ} \pm 28^{\circ}$ (flexion) and $58^{\circ} \pm 28^{\circ}$ (abduction) to $99^{\circ} \pm 46^{\circ}$ (flexion) and $107^{\circ} \pm 39^{\circ}$ (abduction). The first three patients shown in Table 1 (all three had adhesive capsulitis) had significant atrophy of the rotator cuff muscles, as well as such limited ROM that they did not notice loss of motor function with either local anesthetic 


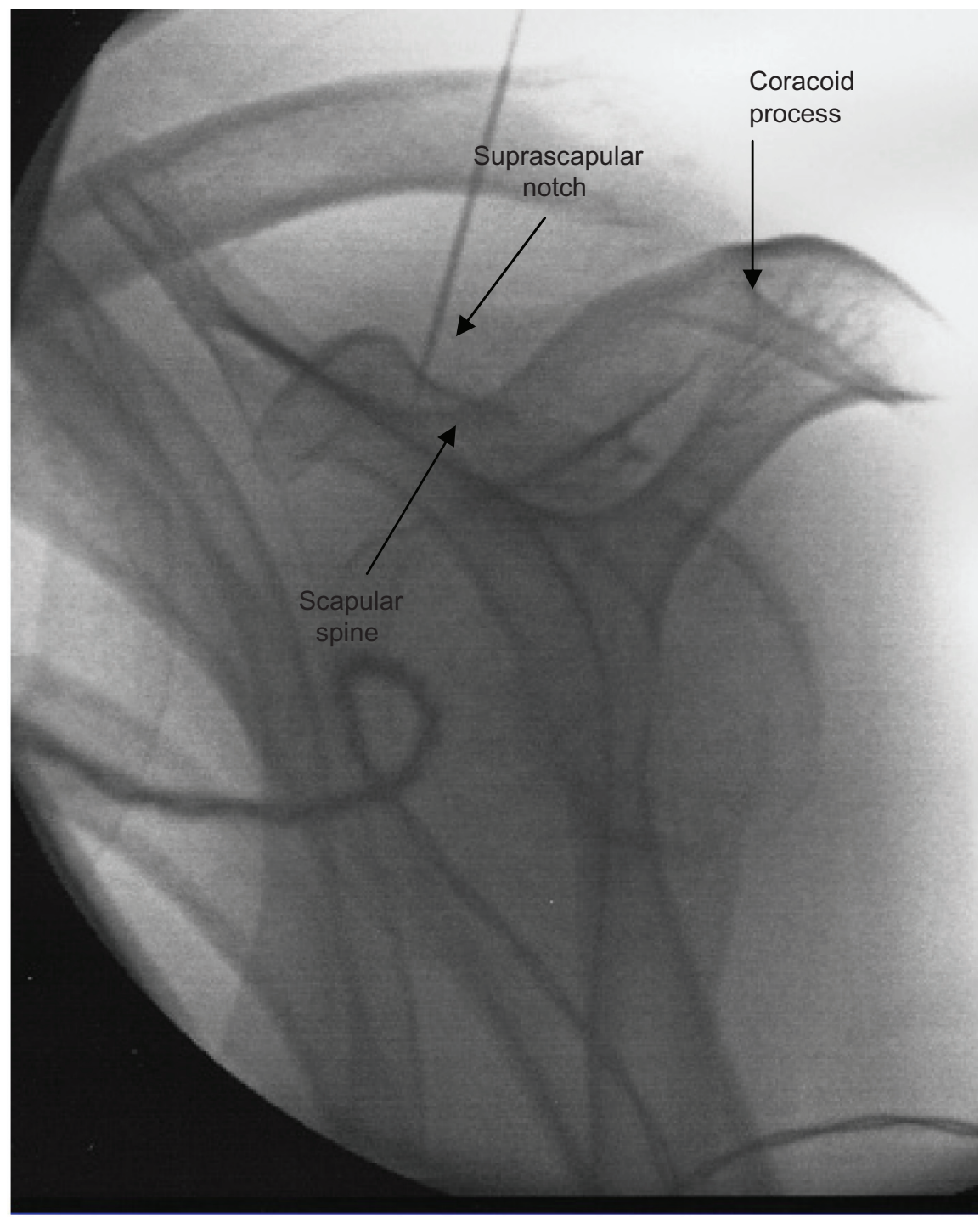

Figure 2 Radiofrequency cannula placed in the wide, blunted V-shaped notch with the patient in the sitting position.

blockade or thermocoagulation of the SSN. The last three patients shown in Table 1 also had significant atrophy of the rotator cuff muscles, with one of the patients having total disruption of the supraspinatus and infraspinatus tendons, and they did not experience weakness on local anesthetic blockade, even with 5\% lidocaine. On follow-up evaluation, the ROM was improved, and neither the patients nor the examining physician could notice increased weakness, even after repeat CRF treatments. There were no persistent dysesthesias or worsening pain, even on recurrent CRF lesioning of the SSN.

\section{Discussion}

This report retrospectively describes a small group of patients who have documented consistent pain relief through thermocoagulation of the SSN. These carefully selected patients had experienced prior local anesthetic blockade of the SSN without clinically apparent loss of function, and the physical examination of these patients was suggestive of atrophy and loss of use of the infraspinatus and supraspinatus muscles. PRF treatment was the immediate second choice of therapy for prolonged relief once blockade of the SSN with local anesthetic and depot methylprednisolone acetate proved clinically effective, but was short-lived. This is the first case series to evaluate the potential effectiveness of CRF of the SSN when pain relief from prior PRF treatment was also too short-lived to be clinically meaningful. The authors acknowledge the bias when reporting retrospectively on a small case series with heterogeneous causes of shoulder pain.

Historically, chronic shoulder pain has been a challenging problem for the patient and the physician because of the limited options available for prolonged pain relief and chance for improved function. Chronic shoulder pain is exceeded 


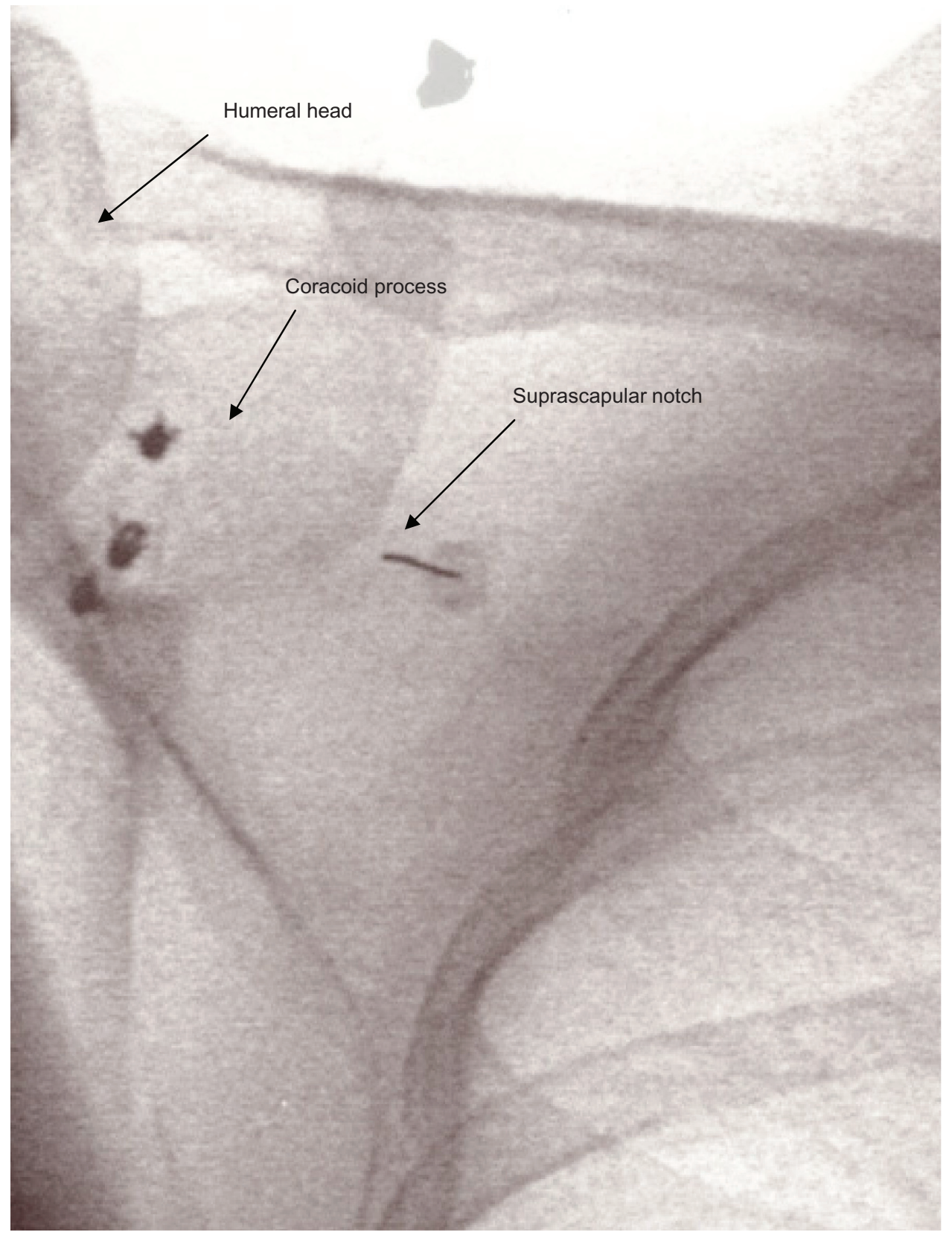

Figure 3 Radiofrequency cannula placed in the classic U-shaped notch with the patient in the prone position.

in clinical prevalence only by back pain, neck pain, and headache. ${ }^{10}$ Traditionally, chronic shoulder pain commonly due to glenohumeral arthritis, adhesive capsulitis, or rotator cuff tears has not been amenable to interventional techniques. Once a patient exhausts the conventional options of physical therapy, anti-inflammatory medications, intra-articular injections, and corrective/reconstructive surgery, persistent pain is not uncommonly managed with long-term opioids. Thus, few patients are referred to pain management clinics.

The SSN has become a target of intervention because of its extensive sensory nerve supply to the shoulder structures, including the posterior glenohumeral joint capsule, acromioclavicular joint, subacromial bursa, and coracoclavicular ligament. ${ }^{11}$ This mixed motor-sensory nerve arises from the upper trunk on the brachial plexus (containing mainly $\mathrm{C} 5$ and C6 fibers) and then courses inferiorly, laterally, and posteriorly to enter the supraspinatus fossa via the suprascapular notch. After supplying the supraspinatus muscle, the nerve curves around the spinoglenoid notch to innervate the infraspinatus muscle. The suprascapular notch is an important structure to identify on fluoroscopy, and clinicians should be aware of the two most common morphologies of the notch that 
Table I Demographics of six patients with chronic shoulder pain who underwent continuous radiofrequency lesioning of the suprascapular nerve

\begin{tabular}{|c|c|c|c|c|c|c|}
\hline Patient & Age (years) & Sex & $\begin{array}{l}\text { Duration of pain } \\
\text { (years) }\end{array}$ & Diagnosis & Etiology of condition & Surgery \\
\hline I & 67 & M & 3 & Adhesive capsulitis & $\begin{array}{l}\text { Right-sided stroke, trauma, } \\
\text { immobilization }\end{array}$ & $\begin{array}{l}\text { MUA, arthroscopic } \\
\text { LOA }\end{array}$ \\
\hline 2 & 54 & $\mathrm{~F}$ & 3 & Adhesive capsulitis & $\begin{array}{l}\text { Right-sided stroke, } \\
\text { immobilization }\end{array}$ & None \\
\hline 3 & 37 & $\mathrm{~F}$ & 2 & Adhesive capsulitis & Trauma, CRPS I & $\begin{array}{l}\text { Arthroscopic LOA } \\
\text { and capsular release }\end{array}$ \\
\hline 4 & 44 & M & 2 & $\begin{array}{l}\text { Glenohumeral } \\
\text { osteoarthritis, prior } \\
\text { bankart lesion }\end{array}$ & $\begin{array}{l}\text { Left hemiparesis following } \\
\text { meningitis }\end{array}$ & Bankart repair \\
\hline 5 & 78 & M & 1 & Rotator cuff tear & $\begin{array}{l}\text { Unrepairable full-thickness } \\
\text { tears of supraspinatus and } \\
\text { infraspinatus tendons }\end{array}$ & Attempted repair \\
\hline 6 & 44 & $\mathrm{~F}$ & 3 & $\begin{array}{l}\text { Glenohumeral } \\
\text { osteoarthritis }\end{array}$ & $\begin{array}{l}\text { Proximal humeral head } \\
\text { resection, chondrosarcoma }\end{array}$ & $\begin{array}{l}\text { Bankart repair, } \\
\text { intralesional curettage }\end{array}$ \\
\hline
\end{tabular}

Abbreviations: CRPS I, complex regional pain syndrome type I; F, female; LOA, lysis of adhesions; M, male; MUA, manipulation under anesthesia.

have been described. ${ }^{12}$ The wide, blunted V-shaped notch is present in $39 \%$ of individuals (Figure 2), while the more classic, symmetrical U-shaped notch is seen in $48 \%$ (Figure 3). SSNB in the management of degenerative shoulder joint disease is felt to be a safe and effective treatment according to a previous randomized, double-blind, placebocontrolled trial. ${ }^{13}$ The proportion of patients experiencing pain relief at months rather than weeks post SSNB was as high as $55 \%$ of all patients initially treated. However, other authors have reported a shorter duration of pain relief post SSNB, where only $29 \%$ of patients reported noticeable pain relief at 3 weeks. ${ }^{14}$

Prior to the application of PRF to the SSN, percutaneous neurolysis with either cryoablation or phenol of the SSN has been described previously. ${ }^{15,16}$ Using $6 \%$ phenol, Lewis ${ }^{16}$ documented a reduction in pain intensity and an improved ROM in flexion and abduction. In the present study the authors also observed improvements in active ROM without loss of function. To reconcile this observation, it is important to realize that abduction and external rotation are not exclusively dependent on the supraspinatus and infraspinatus muscles, respectively. ${ }^{17}$ The middle and anterior deltoid muscle and the serratus anterior muscle are involved in abduction. The teres minor muscle and the posterior portion of the deltoid muscle are responsible, in addition to the infraspinatus, for external rotation. Therefore, lesioning of motor nerve fibers to half of the rotator muscles does not consistently result in functional deterioration; rather, it results in improvement, because complimentary muscles are employed in the setting of pain reduction.

CRF treatment was chosen over chemical neurolysis or cryoanalgesia for several reasons. The spread of chemical neurolytic agents cannot be controlled precisely because they negatively impact adjacent structures via protein denaturation. CRF treatment causes small focal lesions and can be repeated with reproducible results over time, as the authors observed in the case series. CRF treatment is regarded as a safe ablative therapy with a low incidence of complications. ${ }^{18}$

Table 2 Time-sensitive improvement of pain intensity and range of motion (ROM) using suprascapular nerve radiofrequency lesioning

\begin{tabular}{lllllll}
\hline Patient & $\begin{array}{l}\text { Pre-treatment } \\
\text { NRS score }\end{array}$ & $\begin{array}{l}\text { Post-treatment } \\
\text { NRS score } \\
\text { (at 5-7 weeks) }\end{array}$ & $\begin{array}{l}\text { Pre-treatment } \\
\text { ROM } \\
\text { [F/A] }\end{array}$ & $\begin{array}{l}\text { Post-treatment } \\
\text { ROM } \\
\text { [F/A] }\end{array}$ & $\begin{array}{l}\text { Duration of relief } \\
\text { (months) }\end{array}$ & $\begin{array}{l}\text { Repeat procedures } \\
\text { (n) }\end{array}$ \\
\hline 1 & 7 & 2 & $60^{\circ} / 60^{\circ}$ (P) & $90^{\circ} / 90^{\circ}(\mathrm{P})$ & 18 & 1 \\
2 & 9 & 4 & $60^{\circ} / 50^{\circ}$ (P) & $80^{\circ} / 80^{\circ}(\mathrm{P})$ & 4 & 2 \\
3 & 6 & 2 & $20^{\circ} / 20^{\circ}$ (P) & $45^{\circ} / 90^{\circ}(\mathrm{P})$ & 4 & 3 \\
4 & 6 & 3 & $90^{\circ} / 90^{\circ}$ (A) & $120^{\circ} / 120^{\circ}(\mathrm{A})$ & 3 & 1 \\
5 & 7 & 3 & $90^{\circ} / 90^{\circ}$ (A) & $180^{\circ} / 180^{\circ}(\mathrm{A})$ & 6 & 2 \\
6 & 8 & 4 & $40^{\circ} / 40^{\circ}$ (A) & $80^{\circ} / 80^{\circ}$ (A) & 6 & 2 \\
\hline
\end{tabular}

Abbreviations: A, active; F/A, flexion and abduction; NRS, numeric rating scale; $P$, passive. 
Radiofrequency was chosen over cryoablation because of ease of use, probe size, and the potential for lesioning of sensory fibers over motor fibers. While the preclinical studies support the indiscriminate radiofrequency lesioning of both motor and sensory fibers, lesioning of the trigeminal nerve for trigeminal neuralgia suggests otherwise. ${ }^{19}$ Specifically, Tew and Taha $^{19}$ reported on 1200 cases of trigeminal neuralgia with a masticatory muscle weakness rate of $23 \%$.

\section{Conclusion}

In summary, this report suggests that percutaneous CRF lesioning of the SSN may be effective for refractory shoulder pain. Conventional thermocoagulation methods may extend the duration of pain relief in patients for whom less destructive methods such as depot steroids or PRF treatment prove inadequate. Careful evaluation and selection of patients for this procedure is necessary in order to obtain optimal clinical outcomes.

\section{Disclosure}

The authors report no conflicts of interest in this work. The authors did not receive any grants, and this material has not been presented or submitted previously.

\section{References}

1. Uhl RL. Shoulder pain. In: Smith HS, editor. Current Therapy in Pain. Philadelphia, PA: Saunders Elsevier; 2009:147-151.

2. Pitkin GP. Therapeutic nerve block. In: Pitkin GP, editor. Conduction Anesthesia. Philadelphia, PA: JB Lippincott; 1946:884-886.

3. Karataş GK, Meray J. Suprascapular nerve block for pain relief in adhesive capsulitis: comparison of 2 different techniques. Arch Phys Med Rehabil. 2002;83(5):593-597.

4. Chan CW, Peng PW. Suprascapular nerve block: a narrative review. Reg Anesth Pain Med. 2011;36(4):358-373.
5. Shah RV, Racz GB. Pulsed mode radiofrequency lesioning of the suprascapular nerve for the treatment of chronic shoulder pain. Pain Physician. 2003;6(4):503-506.

6. Rohof OJ. Radiofrequency treatment of peripheral nerves. Pain Pract. 2002;2(3):257-260.

7. Eyigor C, Eyigor S, Korkmaz OK, Uyar M. Intra-articular corticosteroid injections versus pulsed radiofrequency in pain shoulder: a prospective, randomized, single-blinded study. Clin J Pain. 2010;26(5):386-392.

8. Erdine S, Yucel A, Cimen A, Aydin S, Sav A, Bilir A. Effects of pulsed versus conventional radiofrequency current on rabbit dorsal root ganglion morphology. Eur J Pain. 2005;9(3):251-256.

9. Farrar JT, Young JP Jr, LaMoreaux L, Werth JL, Poole RM. Clinical importance of changes in chronic pain intensity measured on an 11-point numerical pain rating scale. Pain. 2001;94(2):149-158.

10. Bland JH, Merrit JA, Boushey DR. The painful shoulder. Semin Arthritis Rheum. 1977;7(1):21-47.

11. Aszmann OC, Dellon AL, Birely BT, McFarland EG. Innervation of the human shoulder joint and its implications for surgery. Clin Orthop Relat Res. 1996;330:202-207.

12. Romeo AA, Rotenberg DD, Bach BR Jr. Suprascapular neuropathy. J Am Acad Orthop Surg. 1999;7(6):358-367.

13. Shanahan EM, Ahern M, Smith M, Wetherall M, Bresnihan B, FitzGerald O. Suprascapular nerve block (using bupivacaine and methylprednisolone acetate) in chronic shoulder pain. Ann Rheum Dis. 2003;62(5):400-406.

14. Schneider-Kolsky ME, Pike J, Connell DA. CT-guided suprascapular nerve blocks: a pilot study. Skeletal Radiol. 2004;33(5):277-282.

15. Trescot AM. Cryoanalgesia in interventional pain management. Pain Physician. 2003;6(3):345-360.

16. Lewis RN. The use of combined suprascapular and circumflex (articular branches) nerve blocks in the management of chronic arthritis of the shoulder joint. Eur J Anaesthesiol. 1999;16(1):37-41.

17. Hoppenfeld S. Physcial examination of the shoulder. In: Hoppenfeld S, editor. Physical Examination of the Spine and Extremities. Norwalk, CT: Appleton and Lange; 1976:1-34.

18. Weinbren J, Chan V. Complications of regional anesthesia and chronic pain therapy. In: Finucane BT, editor. Complication of Regional Anesthesia. New York, NY: Churchill Livingstone; 1999:139-169.

19. Tew JM, Taha JM. Percutaneous rhizotomy in the treatment of intractable facial pain (trigeminal, glossopharyngeal, and vagal). In: Schmidek HH, Sweet WH, editors. Operative Neurosurgical Techniques. Philadelphia, PA: WB Saunders; 1995:1469-1484.
Journal of Pain Research

\section{Publish your work in this journal}

The Journal of Pain Research is an international, peer-reviewed, open access, online journal that welcomes laboratory and clinical findings in the fields of pain research and the prevention and management of pain. Original research, reviews, symposium reports, hypothesis formation and commentaries are all considered for publication.

\section{Dovepress}

The manuscript management system is completely online and includes a very quick and fair peer-review system, which is all easy to use. Visit http://www.dovepress.com/testimonials.php to read real quotes from published authors. 